\title{
Clinical factors associated with a conservative gait pattern in older male veterans with diabetes James S Wrobel ${ }^{* 1}$, Ryan T Crews ${ }^{1}$ and John E Connolly ${ }^{2}$
} \author{
Science, North Chicago, Illinois, USA and ${ }^{2}$ VAM\&ROC White River Junction, Vermont, USA \\ Email: James S Wrobel* - james.wrobel@rosalindfranklin.edu; Ryan T Crews - ryan.crews@rosalindfranklin.edu; \\ John E Connolly - john.connolly@va.gov \\ * Corresponding author
}

Address: ${ }^{1}$ Center for Lower Extremity Ambulatory Research at Scholl College of Podiatric Medicine, Rosalind Franklin University of Medicine and

Published: 23 April 2009

Journal of Foot and Ankle Research 2009, 2:1 I doi:10.1 186/1757-II46-2-II

This article is available from: http://www.jfootankleres.com/content/2/I/II

(C) 2009 Wrobel et al; licensee BioMed Central Ltd.

This is an Open Access article distributed under the terms of the Creative Commons Attribution License (http://creativecommons.org/licenses/by/2.0), which permits unrestricted use, distribution, and reproduction in any medium, provided the original work is properly cited.
Received: 7 May 2008

Accepted: 23 April 2009

\begin{abstract}
Background: Patients with diabetes and peripheral neuropathy are at higher risk for falls. People with diabetes sometimes adopt a more conservative gait pattern with decreased walking speed, widened base, and increased double support time. The purpose of this study was to use a multivariate approach to describe this conservative gait pattern.

Methods: Male veterans (mean age $=67$ years; $S D=9.8 ;$ range 37-86) with diabetes $(n=152)$ participated in this study from July 2000 to May 200I at the Veterans Affairs Medical Center, White River Junction, VT. Various demographic, clinical, static mobility, and plantar pressure measures were collected. Conservative gait pattern was defined by visual gait analysis as failure to demonstrate a heel-to-toe gait during the propulsive phase of gait.

Results: Patients with the conservative gait pattern had lower walking speed and decreased stride length compared to normal gait. (0.68 m/s v. $0.91 \mathrm{~m} / \mathrm{s}, p<0.001$; I.04 m v. I.24 m, $p<0.00 \mathrm{l})$ Age, monofilament insensitivity, and Romberg's sign were significantly higher; and ankle dorsiflexion was significantly lower in the conservative gait pattern group. In the multivariate analysis, walking speed, age, ankle dorsiflexion, and callus were retained in the final model describing $36 \%$ of the variance. With the inclusion of ankle dorsiflexion in the model, monofilament insensitivity was no longer an independent predictor.
\end{abstract}

Conclusion: Our multivariate investigation of conservative gait in diabetes patients suggests that walking speed, advanced age, limited ankle dorsiflexion, and callus describe this condition more so than clinical measures of neuropathy.

\section{Background}

Gait alteration in patients with diabetes has been described [1-3]. Patients with diabetes and peripheral neuropathy (DMPN) exhibit gait instability $[4,5]$. While this may appear trivial to the treating clinician, unsteadiness in gait demonstrated the strongest association with depressive symptoms in a study by Vileikyte and col- leagues [6]. Chamberlin and colleagues identified fearful walkers from a Modified Falls Efficacy Scale. They found fearful walkers demonstrated a slower walking speed, shorter stride length, and longer double support time than walkers not identified as fearful [7]. Courtemanche and colleagues observed similar findings in DMPN patients. They found prolonged reaction times leading the authors 
to conclude that there are increased attentional demands with more conservative gait patterns suggesting lack of proprioception affecting control of gait [1]. Yavuzer and colleagues conducted a cross-sectional study of patients with DMPN $(\mathrm{n}=20)$, diabetes $(\mathrm{n}=26)$, and age-genderBMI matched control patients $(n=20)$. They described patients with diabetes having slower gait, shorter steps, limited knee and ankle mobility, and lower plantar flexion moment and power than the control group. These differences were not significant for the DMPN group. Neuropathic patients were defined by electrophysiological testing and it is unclear to what degree this definition is associated with more coarse clinical definitions using monofilaments or vibratory perception threshold testing. The duration of diabetes was similar between the groups at 19 and 15 years. They also found that increased HbA1c and F-wave distal latency were significantly associated with decreased ankle mobility, peak plantar flexion moment and power [3].

While intuition suggests patients with diabetes adopt a more conservative gait pattern to make them feel more stable, they remain at higher risk for falls. Although most falls produce no serious injury, between $5 \%$ and $10 \%$ of community-dwelling fallers do sustain a serious injury with many failing to recover to their pre-injury level of function [8]. In a prospective study of 139 elderly patients in a long-term care facility, Maurer and colleagues looked at falls in multiple domains. These included clinical diagnoses, medications, orthostatic blood pressure change, gait, balance, mental status, well being, activities of daily living, affect, behavior, range of motion, and communication. In the multivariate model, diabetes, gait, and balance remained as significant and independent predictors [9]. Other case-control and cohort studies have described similar findings using multivariate analysis $[9,10]$.

While patients with diabetes may adopt this more conservative gait pattern, we are not aware of any studies that looked at individual clinical attributes in a multivariate model within this specific population. The advantage of a multivariate approach is to control for other measured confounding variables, such as age and neuropathy status. The purpose of this study is to use a multivariate approach to describe this conservative gait pattern.

\section{Methods}

\section{General design and study population}

This study took place from July 2000 to May 2001 at the Veterans Affairs Medical and Regional Office Center, White River Junction, VT. The exact methods have been previously described and are overviewed below [11,12]. Patients were eligible if they were taking an oral hypoglycemic agent or insulin for diabetes and had no current foot ulceration. Patients with active foot and ankle injury, or history of ablative or elective foot surgery were also excluded. Participants signed an informed consent approved by the Committee for Protection of Human Subjects.

\section{Clinical examination}

One examiner and the principal investigator underwent training prior to the inception of the study in order to assure standardization of examination techniques with previously published methods. Age, diabetes duration, smoking status, height, weight, HgbA1c within the past six months was collected prior to the examination. Pedal pulses were palpated and patients with the absence of one or more pulses were considered to have arterial insufficiency[13] Sensitivity to monofilament was determined using a 10 gram monofilament. The patient was insensate if they were unable to detect one or more of the following plantar sites, 1st metatarsal-phalangeal joint (MPJ), 5th MPJ, or hallux [14]. Available dorsiflexion at the ankle was measured as previously described [15]. Briefly, the patient was measured in the supine position with the knee on the frontal plane. The ankle was dorsiflexed maximally with the subtalar joint in a neutral position by palpation. The goniometer was aligned with the lateral column of the foot and lateral lower fibula. Available dorsiflexion at the 1st MPJ was measured passively with the patient standing in a relaxed posture. End range of motion in the dorsiflexed position was felt to be a more informative measure due to current theory in sagittal plane mechanics of the foot [16-18]. The inter-rater reliability, as measured by the intraclass correlation coefficient was 0.71 for the ankle and 0.95 for the $1^{\text {st }}$ MPJ [12].

In a weight-bearing state, the presence of a bunion deformity, hammer toes, foot architecture, and postural sway were determined. Bunion deformity was present if there was abducted great toe position with prominent medial eminence to the 1st MPJ. A hammer toe was defined as a contracted toe requiring a dorsiflexion force to move the digit. Foot architecture, Romberg's test, and joint position sense were performed as previously described $[19,20]$. The presence of a forefoot weight bearing callus was determined. Plantar forefoot fat pad atrophy was defined as a plurality of prominent metatarsal heads readily palpable on the plantar surface of the foot.

An apropulsive gait was defined by visual gait analysis where a patient failed to demonstrate a heel-to-toe gait during the propulsive phase of gait. While the inter-rater reliability of visual gait analysis has been questioned, a study of 20 patients using the observational gait scale, the investigators found moderate to substantial reliability[21] for heel rise with weighted kappas ranging from 0.47 0.78 (intra-rater) and $0.43-0.62$ (inter-rater) [22]. The reliability of describing the push-off in gait after stroke 
was also described as ranging from moderately-high to high in physical therapists. The intraclass correlation coefficient ranged from 0.76 for inter-rater reliability to 0.89 for intra-rater reliability [23]. Walking speed was assessed by measuring the time taken to walk a 10 metre distance following a 3 metre pre-distance to assure constant velocity. Stride length was determined by measuring the distance a foot travels from initial heel contact to heel contact for the next stride of the same foot using a tape measure on the floor. The average of three trials was taken and the patient was coached to walk at their regular walking speed.

\section{Plantar pressure measurement}

Mean dynamic foot pressures were measured using the FScan mat system, software version 4.12F (Tekscan, Boston, MA). Patients were studied using 4-inch stockinette for stockings and without shoes. Calluses were debrided prior to measurement. The mat was calibrated to the patient's weight and the sampling frequency was set at 50 Hz. Maximum peak plantar pressures for the entire foot were obtained using the average of three mid-gait foot steps.

\section{Statistical analysis}

This is secondary analysis of an existing data set. The unit of analysis was the foot rather than the individual. Since the observations were not entirely independent, a general- ized linear model was created using sandwich robust variance estimator and assuming Poisson errors and a log link to estimate relative risk for dichotomous errors. The dependent variable was binary, with 1 depicting the conservative or apropulsive gait pattern and 0 denoting normal propulsive gait. In the first part of the analysis, univariate analysis used a chi squared test with Fisher's Exact test for dichotomous data and one-way analysis of variance for continuous data. The multivariate model was built using a forward stepwise logistic regression with the criterion for removal being a p-value $>0.1$. Of the 152 patients, 40 patients had the conservative gait pattern. Based on this, we nominated 4 a priori covariates for our regression model. These included age, neuropathy status, and dorsiflexion at the ankle and $1^{\text {st }} \mathrm{MPJ}$.

\section{Results}

Patients with the conservative gait pattern had lower walking speed and decreased stride length compared to normal gait. $(0.68 \mathrm{~m} / \mathrm{s} \mathrm{v.} 0.91 \mathrm{~m} / \mathrm{s}, p<0.001 ; 1.04 \mathrm{~m} \mathrm{v} .1 .24$ $\mathrm{m}, p<0.001)$ Table 1 describes the descriptive characteristics of our population and univariate analysis. Age, neuropathy, and Romberg's sign were significantly higher; and ankle dorsiflexion was significantly lower in the conservative gait pattern group. Presence of peripheral arterial disease (as measured by palpable pulses) and callus approached significance. Table 2 describes the multivariate analysis where walking speed, age, ankle dorsiflexion,

Table I: Descriptive characteristics (values are means \pm (SD) unless otherwise stated)

\begin{tabular}{|c|c|c|c|}
\hline & Conservative Gait & Normal Gait & p-value \\
\hline $\mathrm{N}$ & 40 & 264 & \\
\hline Age (yrs) & 73.1 (7.64) & $66.2(9.83)$ & 0.00 \\
\hline Insulin (\% yes) & 36 & 28 & 0.35 \\
\hline $\mathrm{HbAlc}(\%)$ & $7.89(1.37)$ & $7.64(1.69)$ & 0.29 \\
\hline DM Duration (yrs) & $9.5(4.75)$ & $10.1(10.38)$ & 0.73 \\
\hline Smoking History(\% yes) & 92 & 82 & 0.11 \\
\hline Height (mean inches) & $68.5(0.93)$ & $68.4(2.82)$ & 0.95 \\
\hline Weight (mean lbs) & $212(43.95)$ & $211(42.04)$ & 0.85 \\
\hline Ist MPJ ROM (degrees) & $12.1(2.72)$ & $14.2(7.66)$ & 0.13 \\
\hline Bunion deformity (\% yes) & 18 & 17 & 1.00 \\
\hline Hammer toe (\% yes) & 51 & 37 & 0.11 \\
\hline \multicolumn{4}{|l|}{ Foot type (\% yes) } \\
\hline - normal & 46 & 52 & \\
\hline - pronated & 26 & 23 & \\
\hline - supinated & 28 & 25 & \\
\hline Romberg's sign (\% yes) & 26 & 12 & 0.04 \\
\hline Non-palpable pulse (\% yes) & 59 & 43 & 0.06 \\
\hline Insensitivity to 10 gram monofilament (\% yes) & 46 & 27 & 0.02 \\
\hline Absent joint position sense (\% yes) & 5 & 2.6 & 0.35 \\
\hline Ankle DF (degrees) & $3.6(2.07)$ & $5.6(2.93)$ & 0.01 \\
\hline Callus ( $\%$ yes) & 49 & 36 & 0.08 \\
\hline Fat pad atrophy (\% yes) & 31.4 & 47.1 & 0.12 \\
\hline Stride length (metres) & $1.04(0.09)$ & $1.24(0.17)$ & 0.00 \\
\hline Walking speed (metres/second) & $0.68(0.08)$ & $0.91(0.14)$ & 0.00 \\
\hline Peak Pressure $\left(\mathrm{kg} / \mathrm{cm}^{2}\right)$ & $3.8 I(0.73)$ & $3.87(0.87)$ & 0.75 \\
\hline
\end{tabular}


Table 2: Multivariate analysis

\begin{tabular}{|c|c|c|c|c|}
\hline Multivariate Analysis & Risk Ratio & $95 \% \mathrm{Cl}$ & p-value & Pseudo R2 \\
\hline \multicolumn{5}{|l|}{ Model I } \\
\hline $\begin{array}{l}\text { Walking speed } \\
\text { Age in yrs. }\end{array}$ & $\begin{array}{l}0.00 \\
1.09\end{array}$ & $\begin{array}{l}0.00 \text { to } 0.00 \\
1.04 \text { to } 1.15\end{array}$ & $\begin{array}{l}0.00 \\
0.00\end{array}$ & \\
\hline $\begin{array}{l}\text { Callus } \\
\text { Ankle DF (degrees) }\end{array}$ & $\begin{array}{l}3.43 \\
0.86\end{array}$ & $\begin{array}{l}1.38 \text { to } 8.54 \\
0.79 \text { to } 0.96\end{array}$ & $\begin{array}{l}0.01 \\
0.01\end{array}$ & 0.36 \\
\hline \multicolumn{5}{|l|}{ Model 2} \\
\hline $\begin{array}{l}\text { Walking speed } \\
\text { Age in yrs. }\end{array}$ & $\begin{array}{l}0.00 \\
1.09\end{array}$ & $\begin{array}{l}0.00 \text { to } 0.00 \\
1.04 \text { to } 1.15\end{array}$ & $\begin{array}{l}0.00 \\
0.00\end{array}$ & \\
\hline $\begin{array}{l}\text { Callus } \\
\text { Ankle DF (degrees) }\end{array}$ & $\begin{array}{l}3.38 \\
0.86\end{array}$ & $\begin{array}{l}1.35 \text { to } 8.44 \\
0.77 \text { to } 0.97\end{array}$ & $\begin{array}{l}0.01 \\
0.01\end{array}$ & \\
\hline Insensitivity to 10 gram monofilament (\% yes) & 1.15 & 0.47 to 2.83 & 0.75 & 0.36 \\
\hline
\end{tabular}

and callus were retained in the final model (Model 1). This model described about $36 \%$ of the variance around the conservative gait strategy. In a stepwise fashion, walking speed and age described $24.8 \%$ and $4.7 \%$ of the variance respectively. Ankle dorsiflexion and callus described $3.5 \%$ and $2.8 \%$ of the variance respectively.

\section{Discussion}

As far as we know, this is the first published study to use a multivariate approach to study the conservative gait pattern in patients with diabetes. The prevalence of conservative gait in our cohort of elderly diabetic veterans was quite high at $26 \%$. This compares favorably with the results of one study that found $23 \%$ of neuropathic patients reporting unsteadiness [6]. Another study found fearful walkers comprised $24 \%$ of their sample of community dwelling older adults [7].

The univariate analysis described age, neuropathy, Romberg's sign, callus, absent pulse, walking speed, ankle and $1^{\text {st }}$ MPJ dorsiflexion as being associated with the conservative gait pattern. Thinking that neuropathy would lead to an increased fear of falling and subsequently dispose neuropathic individuals to fearful walking, we were surprised that neuropathy was not retained in the multivariate model. We also tried Romberg's sign and absent joint position sense in place of neuropathy thinking that this represented advanced clinical neuropathy. This also was not retained in the final model. The findings are consistent with Yavuzer and colleagues where they did not see any difference between the patients with diabetes and diabetes with neuropathy [3]. These findings are also supported in part by the neuropathy findings of Mueller and colleagues; however, the unloading differences in conservative gait patterns are not found in our work [24]. Additionally, our approach addressed suggestions by the invited commentaries to Mueller et al. that patients without neuropathy and a population of patients that may not have been affected by treatment of foot ulcers be included [24].

Our study has a number of potential limitations. The cross-sectional design and secondary analyses make causal attribution problematic. While the present study is larger than many studies assessing applied biomechanics in patients with diabetes, it is still a select population of predominately male Veterans visiting foot clinics thus potentially limiting generalizability. Effectively, this was a blinded study as examiners were unaware that the conservative gait strategy approach was going to be used in a later analysis. Our neuropathy definitions were also coarse including testing only for monofilament sensitivity, great toe position sense, and Romberg's sign. One could also question the clinical significance of a two degree restriction in statically measured ankle dorsiflexion that was statistically significant. While our inter-rater reliability of this measure was moderate, other authors have described mean absolute differences of two degrees [25]. Other authors have also questioned the role of static measures versus dynamic measures with walking [12].

There are potential clinical implications of the study. Debridement of callus and potential exercise training in this population[26,27] could be investigated regarding their roles in conservative gait strategy. Limited ankle joint dorsiflexion could also be investigated dynamically to observe if this passive limitation persists, whereby the forward momentum of the tibia is restricted [28].

\section{Conclusion}

Our multivariate investigation of conservative gait in diabetes patients suggests that walking speed, advanced age, limited ankle dorsiflexion, and callus describe this condition more so than clinical measures of neuropathy. The clinical implications of this work should be investigated further. 


\section{Competing interests}

The authors disclose no potential conflicts of interest including employment, consultancies, stock ownership, honoraria, paid expert testimony, and patent applications/registrations.

\section{Authors' contributions}

JSW was the primary investigator and contributed to the specific aims, study design, patient examination, statistical analysis, and writing. JEC contributed to the specific aims, study design, and writing. RC contributed to the statistical analysis, interpretation of the results, and writing.

\section{Acknowledgements}

This study was funded by a grant from the Hitchcock Foundation (\#250490). We also thank Joe Duggan, DPM for his assistance with patient recruitment and Jennifer Dercoli, DPM for her assistance with patient examinations.

\section{References}

I. Courtemanche R, Teasdale N, Boucher P, Fleury M, Lajoie Y, Bard C: Gait problems in diabetic neuropathic patients. Arch Phys Med Rehabil 1996, 77:849-855.

2. Sacco IC, Amadio AC: Influence of the diabetic neuropathy on the behavior of electromyographic and sensorial responses in treadmill gait. Clin Biomech (Bristol, Avon) 2003, 18:426-434.

3. Yavuzer G, Yetkin I, Toruner FB, Koca N, Bolukbasi N: Gait deviations of patients with diabetes mellitus: Looking beyond peripheral neuropathy. Eura Medicophys 2006, 42: I 27-I 33.

4. Cavanagh PR, Simoneau GG, Ulbrecht JS: Ulceration, unsteadiness, and uncertainty: The biomechanical consequences of diabetes mellitus. J Biomech 1993, 26(SuppI I):23-40.

5. Resnick HE, Vinik AI, Schwartz AV, Leveille SG, Brancati FL, Balfour J, Guralnik JM: Independent effects of peripheral nerve dysfunction on lower-extremity physical function in old age: The women's health and aging study. Diabetes Care 2000, 23:1642-1647.

6. Vileikyte L, Leventhal H, Gonzalez JS, Peyrot M, Rubin RR, Ulbrecht JS, Garrow A, Waterman C, Cavanagh PR, Boulton AJ: Diabetic peripheral neuropathy and depressive symptoms: The association revisited. Diabetes Care 2005, 28:2378-2383.

7. Chamberlin ME, Fulwider BD, Sanders SL, Medeiros JM: Does fear of falling influence spatial and temporal gait parameters in elderly persons beyond changes associated with normal aging? J Gerontol A Biol Sci Med Sci 2005, 60: I I63-I I 67.

8. Rubenstein LZ, Josephson KR: Falls and their prevention in elderly people: What does the evidence show? Med Clin North Am 2006, 90:807-824.

9. Maurer MS, Burcham J, Cheng $\mathrm{H}$ : Diabetes mellitus is associated with an increased risk of falls in elderly residents of a longterm care facility. J Gerontol A Biol Sci Med Sci 2005, 60: I I 57- I I62.

10. Bueno-Cavanillas A, Padilla-Ruiz F, Jimenez-Moleon J], PeinadoAlonso CA, Galvez-Vargas R: Risk factors in falls among the elderly according to extrinsic and intrinsic precipitating causes. Eur J Epidemiol 2000, 16:849-859.

II. Wrobel JS, Birkmeyer NJ, Dercoli JL, Connolly JE: Do clinical examination variables predict high plantar pressures in the diabetic foot? J Am Podiatr Med Assoc 2003, 93:367-372.

12. Wrobel JS, Connolly JE, Beach ML: Associations between static and functional measures of joint function in the foot and ankle. J Am Podiatr Med Assoc 2004, 94:535-54I.

13. Second european consensus document on chronic critical leg ischemia. Eur J Vasc Surg 1992, 6(Suppl A): I-32.

14. Olmos PR, Cataland S, O'Dorisio TM, Casey CA, Smead WL, Simon SR: The semmes-weinstein monofilament as a potential predictor of foot ulceration in patients with noninsulin-dependent diabetes. Am J Med Sci 1995, 309:76-82.

15. Diamond JE, Mueller MJ, Delitto A, Sinacore DR: Reliability of a diabetic foot evaluation. Phys Ther 1989, 69:797-802.
16. Dananberg H]: Gait style as an etiology to chronic postural pain. Part i. Functional hallux limitus. J Am Podiatr Med Assoc 1993, 83:433-44I.

17. Dananberg HJ: Gait style as an etiology to chronic postural pain. Part ii. Postural compensatory process. J Am Podiatr Med Assoc 1993, 83:6I5-624.

18. Dananberg HJ: Sagittal plane biomechanics. J Am Podiatr Med Assoc 2000, 90:47-50.

19. Walker M, Fan HJ: Relationship between foot pressure pattern and foot type. Foot Ankle Int 1998, 19:379-383.

20. Bickley LSSP: Bates' guide to physical examination and history taking 9th edition. Lippincott Williams \& Wilkins; 2007.

21. Landis JR KG: The measurement of observer agreement for categorical data. Biometrics 1977, 33:159.

22. Mackey AH, Lobb GL, Walt SE, Stott NS: Reliability and validity of the observational gait scale in children with spastic diplegia. Dev Med Child Neurol 2003, 45:4-II.

23. McGinley JL, Goldie PA, Greenwood KM, Olney SJ: Accuracy and reliability of observational gait analysis data: Judgments of push-off in gait after stroke. Phys Ther 2003, 83: I46-160.

24. Mueller MJ, Minor SD, Sahrmann SA, Schaaf JA, Strube MJ: Differences in the gait characteristics of patients with diabetes and peripheral neuropathy compared with age-matched controls. Phys Ther 1994, 74:299-308.

25. Jonson SR, Gross MT: Intraexaminer reliability, interexaminer reliability, and mean values for nine lower extremity skeletal measures in healthy naval midshipmen. J Orthop Sports Phys Ther 1997, 25:253-263.

26. Balducci S, lacobellis G, Parisi L, Di Biase N, Calandriello E, Leonetti $\mathrm{F}$, Fallucca $\mathrm{F}$ : Exercise training can modify the natural history of diabetic peripheral neuropathy. J Diabetes Complications 2006, 20:216-223.

27. Richardson JK, Sandman D, Vela S: A focused exercise regimen improves clinical measures of balance in patients with peripheral neuropathy. Arch Phys Med Rehabil 200I, 82:205-209.

28. Perry J: Gait analysis: Normal and pathological function Ist edition. Thorofare, NJ: Slack Inc; 1992.

\section{Publish with Bio Med Central and every scientist can read your work free of charge}

"BioMed Central will be the most significant development for disseminating the results of biomedical research in our lifetime. "

Sir Paul Nurse, Cancer Research UK

Your research papers will be:

- available free of charge to the entire biomedical community

- peer reviewed and published immediately upon acceptance

- cited in PubMed and archived on PubMed Central

- yours - you keep the copyright

Submit your manuscript here:

http://www.biomedcentral.com/info/publishing_adv.asp
BioMedcentral 